\title{
Unintentional poisoning hospitalisations among young children in Victoria
}

\author{
Julie L Hoy, Lesley M Day, James Tibballs, Joan Ozanne-Smith
}

\begin{abstract}
Objectives-To describe the epidemiology of unintentional childhood poisoning hospitalisation in Victoria, Australia, in order to monitor trends and identify areas for research and prevention.

Methods-For children under 5 years, all Victorian public hospital admissions, July 1987 to June 1995, due to unintentional poisoning by drugs, medicines, and other substances were analysed. Similar cases were also extracted from the database of the Royal Children's Hospital intensive care unit, Melbourne for the years 197991. Log linear regression modelling was used for trend analyses.

Results-The annual average childhood unintentional poisoning rate was 210.7 per 100 000. Annual rates for males consistently exceeded those for females. The most common agents were those acting on the respiratory system and on smooth and skeletal muscles (muscle relaxants, cough and cold medicines, antiasthmatics), aromatic analgesics (paracetamol), and systemic agents (including antihistamines).

Further investigation is justified for cardiac agents, some respiratory agents, and asthma medications.

Conclusions-Childhood poisoning hospitalisation rates have not decreased in Victoria over recent years. A focused, agent specific approach, as well as a series of generic measures for the prevention of poisoning to children under 5 is advocated. The ongoing surveillance, collection and analysis of data, in addition to research on specific poisoning agents are essential components of any prevention strategy.
\end{abstract}

Public Health Division, Department of Human Services, Victoria

J L Hoy

Monash University Accident Research Centre, Building 70, Monash University, Wellington Road, Clayton, Victoria 3168, Australia

L M Day

J Ozanne-Smith

Intensive Care Unit, Royal Children's

Hospital, Victoria J Tibballs

Correspondence to: Dr Day.
A consistent observation in the literature that childhood poisoning is a heterogeneous issue with many individual agents contributing to the overall problem. ${ }^{10}{ }^{13-16}$ This suggests that further gains in the reduction of poisoning will require focus on a number of individual poisoning agents, in addition to the consideration of further generic measures. One aspect of childhood poisoning which has received little attention is the way in which children gain access to poisoning agents.

The Childhood Poisoning Research and Prevention Project was designed to address these issues by (1) describing the dimensions of childhood poisoning among children under 5 years of age, (2) identifying poisoning agents for further study on the basis of frequency, severity, and potential for prevention, (3) identifying the mechanisms of access for specific agents, and (4) identifying potential prevention strategies. Here we report on the first two objectives. Studies addressing the latter two objectives have been published elsewhere. ${ }^{17-23}$

\section{Method}

This study was designed to provide descriptive data and trend analyses for all children under 5 years admitted to public hospitals as a result of unintentional poisoning for a period of eight years in Victoria, Australia.

Two databases were used, the first holding information on all hospital admissions, and the second on admissions to the intensive care unit of the largest paediatric hospital.

Monash University Accident Research Centre holds a subset of the Victorian Inpatient Minimum Database (VIMD) records, ${ }^{24}$ selected by external cause of injury codes ( $\mathrm{E}$ codes) from the International Classification of Diseases, ninth revision, clinical modification (ICD9-CM). ${ }^{25}$

We extracted cases of children less than 5 years of age admitted to public hospitals by the ICD9-CM E code relating to unintentional poisoning by drugs, medicinal substances, biologicals, other solid and liquid substances, gases, and vapours (E850.0-E858.9 and E860.0-E869.9). ${ }^{25}$ Data were extracted from July 1987 to June 1995 . Readmissions to the same public hospital were excluded. ${ }^{24}$ Transfers between public hospitals could not be excluded, but previous estimates of these occurrences were shown to be insignificant. ${ }^{7}$ Variables included age, sex, agent of poisoning, length of hospital stay, and place where poisoning occurred.

The intensive care unit of the Royal Children's Hospital, Melbourne, holds a database of admissions from which cases of unintentional poisoning among children less than 5 years of age were identified for the years 1979-91. Additional information was ex- 
Table 1 Age and sex specific childhood poisoning hospitalisation rates, Victoria, 1987-88 to 1994-95

\begin{tabular}{lccr}
\hline & \multicolumn{3}{c}{ Average annual rate per 100000} \\
\cline { 2 - 4 } Age (years) & Males & Females & \multicolumn{1}{c}{ All } \\
\hline$<1$ & 102.3 & 88.1 & 94.5 \\
1 & 354.3 & 318.2 & 336.7 \\
2 & 439.9 & 340.5 & 391.4 \\
3 & 183.7 & 156.3 & 170.3 \\
4 & 67.8 & 51.5 & 59.9 \\
All & 229.6 & 150.9 & 210.7 \\
\hline
\end{tabular}

tracted from the medical records and entered onto the database to enhance the detail available for each case. Variables included age, sex, poisoning agent, symptoms, treatment given, complications, outcome, length of stay, and circumstances of ingestion (where recorded). The intensive care unit database and the VIMD were not linked.

The population denominators, all Victorian children under 5 years, were derived from Australian Bureau of Statistics population estimates for Victoria from June 1987 to June 1995. Mean annual rates were calculated from the average of individual annual rates.

The statistical package SPSS-X was used to extract data and conduct univariate and bivariate analyses. ${ }^{26}$ Trend analyses were carried out with SAS using log linear regression modelling with correction for overdispersion and transferred to Excel to calculate $95 \%$ confidence intervals (CI). ${ }^{27}$

\section{Results}

HOSPITAL ADMISSIONS, VICTORIA

Rates and frequencies

During the period from 1987 to 1995 there were 5324 public hospital admissions as a result of unintentional poisoning of children under 5 years. This accounted for $16.8 \%$ of all hospital admissions for injury in this age group. The average annual rate of hospital admissions per year was 210.7 per 100000 .

For the eight year period there was an upward trend for the unintentional poisoning rate $(\beta=0.03$, CI 0.01 to 0.05$)$. No fatalities were recorded for children admitted to public hospitals during this period.

\section{Age and gender}

The hospitalisation rate and frequency for males exceeded that for females (table 1). The peak frequency occurred at ages 1 and 2, for boys and girls, accounting for $37 \%$ and $32 \%$ of cases, respectively. Boys had more ingestions than girls for all drug groups except psychotropics (E854), sedatives and hypnotics (E852), antibiotics and other anti-infectives (E856, E857).

\section{Poisoning agents}

Seventy three per cent of poisoning hospitalisations were due to ingestions of drugs, medications, or biological substances. The remainder was mostly due to domestic chemicals.

Four digit $\mathrm{E}$ codes are used to describe the 10 agent groups most often involved in poisoning (table 2). Specific drugs cannot be identified from the VIMD, with the exception of paracetamol, the only drug currently available in Australia that is classified as E850.5. Other drugs that could be classified into this group have not been marketed in Australia for some time. Of the 10 major agent groups resulting in hospitalisation, evidence of an upward trend was found for three and a downward trend for two groups (table 2). Also of concern was the upward trend found for rodenticides ( $\beta=0.11$, CI 0.03 to 0.19$)$ and antidepressants ( $\beta=0.08 \mathrm{CI} 0.02$ to 0.15 ).

\section{Severity of poisoning}

Ninety seven per cent of admissions due to poisoning are less than three days' duration. Eight agent groups resulting in length of stay greater than two days caused $44 \%$ of these longer admissions (table 3 ). No single E code group accounted for more than $9 \%$ of these longer stays.

\section{Place of poisoning}

In $61.4 \%$ of cases, poisoning occurred within the home. For a further $36.3 \%$ of cases the location was unknown.

INTENSIVE CARE ADMISSIONS, ROYAL CHILDREN'S HOSPITAL

\section{Rates and frequencies}

A total of 250 admissions to the intensive care unit was recorded between 1979-91, an annual average of 19 . Poisoning accounted for between 1.1 and $3.3 \%$ of all intensive care unit admissions. The only fatality was a 2 year old child who died after ingesting carbamazepine.

\section{Age and gender}

Admission frequency to the intensive care unit was greater for boys (53.6\%) than girls $(45.6 \%)$. As with hospital admissions, the peak frequencies were at ages 1 and 2 years $(34 \%, 32 \%)$.

\section{Poisoning agents}

Sixty per cent of intensive care unit admissions were a result of drug ingestions. Eight agent groups (based on four digit E codes) were

Table 2 Trend in and distribution of childhood (<5 years age) poisoning hospitalisation by external cause of injury code (E code), Victoria, 1987-88 to 1994-95

\begin{tabular}{|c|c|c|c|c|c|}
\hline E code & Description of agents covered by $E$ code & Frequency & $\%$ & $\beta$ (slope) & $95 \%$ CI for $\beta$ \\
\hline 858.6 & Respiratory system, smooth and skeletal muscle agents & 496 & 9.3 & 0.05 & 0.01 to 0.1 \\
\hline 850.4 & Aromatic analgesics & 482 & 9.1 & 0.15 & 0.11 to 0.19 \\
\hline 858.1 & Systemic agents & 327 & 6.1 & 0.07 & 0.000 to 0.14 \\
\hline 858.7 & Skin and mucous membrane, ear, nose, throat and dental drugs & 280 & 5.3 & -0.09 & -0.15 to -0.02 \\
\hline 858.3 & Cardiovascular system agents & 274 & 5.2 & 0.02 & 0.06 to 0.09 \\
\hline 853.2 & Benzodiazepine based tranquillisers & 259 & 4.9 & -0.04 & -0.14 to 0.05 \\
\hline 855.5 & Sympathomimetics (adrenergics) & 209 & 3.9 & 0.03 & -0.05 to 0.1 \\
\hline 863.4 & Unspecified insecticides & 178 & 3.3 & 0.06 & -0.01 to 0.12 \\
\hline 855.0 & Anticonvulsant and antiparkinsonism drugs & 169 & 3.2 & -0.07 & -0.13 to -0.01 \\
\hline 858.2 & Agents affecting blood constituents & 137 & 2.6 & -0.04 & -0.11 to 0.02 \\
\hline
\end{tabular}


Table 3 Main poisoning agents associated with length of hospital stay greater than two days, childhood poisoning (<5 years age), Victoria, 1987-88 to 1994-95

\begin{tabular}{llll}
\hline E code & Agent & Frequency & $\begin{array}{l}\text { \% of all longer } \\
\text { admissions }\end{array}$ \\
\hline 853.2 & Benzodiazepine based tranquillisers & 14 & 8.7 \\
855.0 & Anticonvulsant, antiparkinsonism drugs & 12 & 7.5 \\
850.4 & Aromatic analgesics & 10 & 6.2 \\
853.0 & Phenothiazine based tranquillisers & 10 & 6.2 \\
853.1 & Butyrophenone based tranquillisers & 7 & 4.3 \\
854.0 & Antidepressants & 6 & 3.7 \\
858.3 & Cardiovascular system agents & 6 & 3.7 \\
858.7 & Skin and mucous membrane, ear, nose, & 6 & 3.7 \\
& throat and dental drugs & 6 & 3 \\
\hline
\end{tabular}

${ }^{\star}$ Length of stay $>2$ days.

Table 4 Distribution of childhood ( $<5$ years age) poisoning admissions to intensive care unit by external cause injury code (E code), Royal Children's Hospital, Victoria, 1979-91

\begin{tabular}{llll}
\hline Ecode & Agents & Frequency & $\%$ \\
\hline 858.6 & Respiratory system, smooth and & & \\
& skeletal muscle agents & 27 & 10.8 \\
854.0 & Antidepressants & 24 & 9.6 \\
855.0 & Anticonvulsants & 22 & 8.8 \\
858.3 & Cardiovascular system agents & 19 & 7.6 \\
858.4 & Gastrointestinal system agents & 10 & 4.0 \\
853.0 & Phenothiazine based tranquillisers & 7 & 2.8 \\
852.8 & Specified sedatives, hypnotics & 5 & 2.0 \\
853.2 & Benzodiazepine based tranquillisers & 4 & 1.6 \\
\hline
\end{tabular}

responsible for $47.2 \%$ of these admissions (table 4). Additional information from patient records allowed the identification of individual drugs. Of all antidepressant admissions 83\% were due to tricyclic antidepressants. All admissions for anticonvulsants, and antiparkinsonism drug groups were due to anticonvulsants, and $63.0 \%$ of the agents acting on muscles and respiratory system were eucalyptus based inhalation solutions.

Severity of poisoning

Most intensive care unit admissions (89\%) were of less than three days' duration.

\section{Treatment}

Forty six per cent of patients presented for treatment within two hours of ingestion and $29 \%$ within $2-5$ hours. Mechanical ventilation was required for 34 patients (14\%) and in another five $(2 \%)$ endotracheal intubation without ventilation was used. Therapeutic medication was required for 75 patients $(30 \%)$.

Two hundred and ninety seven treatment measures to prevent absorption of the poison were instituted in 180 patients. Thirty six per cent per cent of induced emesis and gastric lavage treatments were known to have been administered more than one hour after ingestion, the period considered to be most efficacious for these treatments. ${ }^{28}$ Over the period of investigation, the proportion of cases treated with gastric lavage declined from 33\% to $17 \%$. The proportion treated with induced emesis remained constant at approximately $30 \%$. Treatment with activated charcoal increased from $36 \%$ to $71 \%$, and colonic irrigation increased from nil to $9 \%$. Twenty seven patients were treated with antidotes: 16 $(6 \%)$ received naloxone, four $(2 \%)$ received desferrioxamine, four $(2 \%)$ received atropine, and three $(1 \%)$ received pralidoxime.
Access and place of poisoning

Poisoning occurred in the child's own home in $87 \%$ of incidents, and in $64 \%$, the patient had accessed the agent with no apparent help from any other person. Ten per cent were known to have climbed to get the agent.

\section{Long term complications}

Seven children experienced one or more long term complications. These were oesophageal strictures after ingesting corrosive substances (3), persistent drooling after ingesting disinfectant (1), visual impairment after ingesting quinine (1), epilepsy and spastic quadriplegia after poisoning by motor vehicle exhaust gas (1), and decreased motor coordination after ingesting calcium carbonate (1).

\section{Discussion}

his study was limited to hospital admissions which account for $17 \%$ of medically treated childhood poisonings in Victoria. ${ }^{29}$ Other sources of childhood poisoning data in Victoria include the Victorian Injury Surveillance System (VISS) and the Victorian Poisons Information Centre (VPIC). These data sources reflect generally less severe poisoning and relate to emergency department presentations at participating hospitals (VISS), and calls regarding suspected and actual ingestions (VPIC). Unfortunately, it is not currently possible to link these databases to provide a more complete overview of childhood poisoning. Analyses of these data sources for less severe cases have been conducted previously. ${ }^{17}{ }^{21}$ For prevention purposes, a focus on hospitalisation data addresses the more severe end of the spectrum.

The current classification of injury due to poisoning by ICD9 has no firm guidelines. The potential for inconsistent classification exists. ${ }^{30}$ There is some potential for different interpretation of the $\mathrm{E}$ codes by the hospital medical records clerks coding for the VIMD. This is particularly applicable for poisoning as the clustering of drugs into functional groups in the $\mathrm{E}$ code framework creates a situation where the same drug or substance can feasibly be categorised into more than one $\mathrm{E}$ code. ${ }^{30}$ Accuracy studies of the VIMD indicate that the use of $\mathrm{E}$ codes for injury surveillance is feasible and reliable. ${ }^{31}$

An additional limitation of broad $\mathrm{E}$ code categories is that the researcher is unable to identify specific drugs or substances within those categories. The development of a better coding system, or an extension to the ICD9 E codes, would enhance the ability to identify agents involved. When implemented, ICD10 will allow identification of an increased number of subclasses within the current broad $\mathrm{E}$ code categories, and will facilitate more consistent classification. However, identification of specific poisoning agents will still be limited.

Length of stay has limited use as a proxy for injury severity since it excludes those with adverse sequelae who are managed as outpatients, and includes cases of prolonged admission due to non-medical reasons. Other limitations of the VIMD have been documented 
elsewhere. ${ }^{7243}$ The absence of private hospital data for the period of the study would result in minimal bias since an annual average of 11 children under 5 years are admitted to private hospitals in Victoria as a result of unintentional poisoning. ${ }^{33}$

This study confirms that unintentional poisoning in children under 5 years of age in Victoria conforms to the patterns typically found in Westernised countries. These features include the incidence peak of poisoning at 2 years of age, a generally higher incidence in males, most incidents occurring at home, similarity of agents, low mortality, and short length of stay. ${ }^{10}{ }^{13-17}$ 34-37

The broad range of poisoning agents identified here confirms what is reported in other studies, both in Australia and overseas. Of most concern are the drugs or drug groups that occur with high frequency, upward trends, result in longer duration of stay, or in intensive care unit admissions. It is these groups that should be the focus of intensive prevention strategies. However, to develop a focused approach to prevention, a means to identify individual agents within these groups is required.

We used intensive care data from this study, in addition to emergency department presentation data from some Victorian hospitals published elsewhere, ${ }^{17}$ to identify the agents from each of the groups where extra focus is required. Case series studies to identify the mechanisms of access have been conducted for paracetamol, eucalyptus oil, tricyclic antidepressants, benzodiazepine tranquillisers, and rodenticides. ${ }^{17} 192022$ Similar studies are yet to be conducted for cardiovascular drugs, asthma medications, antispasmodics, and cough and cold preparations.

The decreasing trend for anticonvulsants or antiparkinsonism drugs is of interest. Intensive care unit data identified all admissions in this group as carbamazepine, an anticonvulsant. A legislative requirement to have child resistant packaging for carbamazepine since 1989 may explain the welcome trend. Ongoing surveillance would be expected, therefore, to show a continued decreasing trend.

The use of measures to limit absorption were often applied beyond their limits of efficacy. These treatments may, therefore, represent unjustified levels of invasive treatment, increase morbidity, and prolong hospital stay.

\section{Implications for prevention}

The high number of poisoning incidents occurring within the home offers potential for prevention strategies. Efforts need to be aimed at both 1 and 2 year olds, rather than just 2 year olds, the commonly accepted peak age of poisoning.

There are a number of drugs without mandatory requirement for child resistant packaging that are significant in childhood poisoning, including benzodiazepines and other tranquillisers, some cardiac drugs, some asthma medications, and eucalyptus based inhalation solutions. Other drugs, covered by the legislation, still cause significant, and in some cases serious, morbidity. These include paracetamol, tricyclic antidepressants, anticonvulsants, pure eucalyptus oil, and some cardiac drugs. The correct use of child resistant closures and storage of medications in the home require further investigation There may also be a need for improving the efficacy of current child resistant packaging.

We have identified a number of poisoning agents for which further investigation of access by children is justified but has not yet been conducted.

Previous studies have suggested that poisoning prevention is optimal when both safe storage and child resistant packaging are used. ${ }^{37}$ The development and implementation of safe benchtop storage, as suggested elsewhere, ${ }^{17}$ may lead to significant decreases in poisoning. Design of such storage would need to accommodate both bottle and blister/strip packaging.

Funding was provided to Monash University Accident Research Centre (MUARC) by the Victorian Health Promotion Foundation and the Victorian Department of Human Services, through the Public Health Training Scheme. Dr Malcolm Dobbin and $\mathrm{Mr}$ Barry Parsons provided valuable advice. Julie Valuri, Christina Leong, Voula Stathakis, Barb Fox, and Di Holst of MUARC supplied a high standard of technical assistance with data retrieval, coding, and analysis. Dr Frank Shann gave approval to use data from the Royal Children's Hospital intensive care unit. This project was carried out at MUARC.

1 Krug A, Ellis J, Hay I, et al. The impact of child-resistant containers on the incidence of paraffin (kerosene) ingestion in children. $S$ Afr Med $\mathcal{f} 1994 ; 84: 730-4$

2 Rodgers GB. The safety effects of child-resistant packaging for oral prescription drugs. Two decades of experience. for oral prescription drug.

3 Corbett S, Williamson M, Harrison J. Accidental poisoning in the domestic environment. Report to the National Health and Medical Research Council Working Party on Domestic Chemicals, 1991.

4 Sibert JR, Craft AW, Jackson RH. Child resistant packaging and accidental child poisoning. Lancet 1977;ii:289-90.

5 Walton WW. An evaluation of the poisoning prevention packaging act. Pediatrics 1982;69:363-70.

6 O’Brien JF. Queensland progress in achieving national health ooals and targets for preventable mortality and morbidity. Brisbane: Epidemiology and Health Information Branch, Queensland Health, 1993.

7 Watt G. Hospitalised injuries Victoria, Fuly 1987-fune 1993. Melbourne: Monash University Accident Research Centre, 1995. Report No 67.

8 Department of Human Services and Health. Injury in Australia - an epidemiological review. Canberra: Australian Government Publishing Service, 1994.

9 Health Department of Western Australia. Injury in Western Australia. Perth: Health Department of Western Australia, 1991

10 Campbell D, Oates RK. Childhood poisoning - a changing profile with scope for prevention. Med F Aust 1992;156: $238-40$.

11 Nolan T, Penny M. Epidemiology of non-intentional injuries in an Australian urban region: results from injury surveillance. F Paediatr Child Health 1992;28:27-35.

12 Nutbeam D, Wise M, Bauman A, et al. Goals and targets for Australia's health in the year 2000 and beyond. Canberra: Commonwealth Department of Health, Housing and Human Services, 1993.

13 Melis K, Bochner A. Acute poisoning in a children's hospital: an 8 year experience. Acta Clinica Biologica. Supplementum 1990;13:98-100.

14 Lacroix J, Gaudreault P, Gauthier M. Admission to a pediatric intensive care unit for poisoning: a review of 105 atric intensive care unit for poisoning:
cases. Crit Care Med 1989;17:748-50.

15 Petridou E, Polychronopoulou A, Kouri N, et al. Unintentional childhood poisoning in Athens: a mirror of consumerism? F Toxicol Clin Toxicol 1997;35:669-75.

16 Repetto MR. Epidemiology of poisoning due to pharmacological products, Poison Control Centre, Seville, Spain. Eur F Epidemiol 1997;13:353-6.

17 Routley V, Ozanne-Smith J, Ashby K. Poisonings in early childhood. Melbourne: Monash University Accident Research Centre. Hazard 1996;27.

18 Ozanne-Smith J, Day L, Parsons B, et al. Poisoning prevention. Proceedings of the Third International Conference on Product Safety Research. March 6-7, 1995. Amsterdam: European Consumer Safety Association, 1995.

19 Parsons B, Day L, Ozanne-Smith J, et al. Rodenticide poisoning among young children: mechanisms of access and the potential for prevention. Australian and New Zealand fournal of Public Health 1996;20:488-92. 
20 Day L, Ozanne-Smith J, Parsons B, et al. Eucalyptus oil poisoning among young children: mechanisms of access and the potential for prevention. Australian and New Zealan fournal of Public Health 1997;21:297-302.

21 Cornish LS, Parsons BJ, Dobbin MD. Automatic dishwasher detergent poisoning. Australian and New Zealand fournal of Public Health 1996;20:278-82.

22 Tibballs J. Clinical effects and management of eucalyptus oil ingestion in infants and young children. Med $\mathcal{F}$ Aust 1995; 163: $177-80$.

23 Tibballs J. Eucalyptus oil-medicinal therapy or folk remedy? Australian fournal of Hospital Pharmacy 1995;25 $701-4$.

24 Watt GM, Ozanne-Smith J. Trends in public hospital admission rates, Victoria, July 1987 to June 1993. Australian and New Zealand Fournal of Public Health 1996;20:393-401.

25 United States Department of Health. International classifcation of diseases, 9th revision. Clinical modification (ICD-9cation of diseases, 9th revision. Clinical modification (ICD-9and Hospital Activities, 1988 .

26 SPSS-X Version 4.1 (computer program). Chicago: SPSS Inc, 1988 .

27 SAS Institute Inc. SAS/STAT (computer program). SAS technical report. The GLENMOD procedure. Release 6.09 . Cary, NC: SAS Institute Inc, 1993: 243.

28 Tibballs J. Poisoning and envenomation. In: Efron D, ed. Paediatric handbook. 5th Ed. Melbourne: Blackwell Science, 1995: 12-18.
29 Watson W, Ozanne-Smith J. The cost of injury in Victoria. Melbourne: Monash University Accident Research Centre, Melbourne: Monash Uni

30 Cummings P, Koepsell TD, Mueller BA. Methodological challenges in injury epidemiology and injury prevention research. Annu Rev Public Health 1995;16:381-400.

31 MacIntyre CR, Ackland MJ, Chandraraj EJ. Accuracy of injury coding in Victoria hospital morbidity data. Australian and New Zealand fournal of Public Health 1997;21:779-82.

32 Watt G. Injuries sustained by young people in Victoria, 1986-1992. Melbourne: Monash University Accident Research Centre, 1992. Report No 43.

33 Watt G. Private hospital injury admissions Victoria, fanuary 1993-fune 1994: a comparison with public hospitals. Melbourne: Monash University Accident Research Centre, 1995. Report No 71.

34 Yamamoto LG, Wiebe RA, Mathews WJ. Toxic exposures and ingestions in Honolulu: I. A prospective pediatric ED cohort; II. A prospective poison centre cohort. Pediatr Emerg Care 1991;7:141-8.

35 Waldman HD. The poisoning of our children. fournal of Dentistry for Children 1993;27:132-5.

36 Ozanne-Smith J. Child injury prevention. In: Ozanne-Smith $\mathrm{J}$, Williams $\mathrm{F}$, eds. Injury research and prevention: a text. Melbourne: Monash University Accident Research Centre, 1995.

37 Wiseman H. Accidental childhood poisoning. Health Visitor 1995;68:163-4.

A young woman was burned after striking the top of an egg she had boiled in water in a microwave oven. To avoid this type of injury, manufacturers recommend piercing the shell first; ideally the yolk should be pierced as well. Most manuals warn that eggs should not be cooked with an intact shell in the instruction pages, but fail to reiterate this information in the recipe pages (Burns 1998;24:585-6).

Seventy three cases, including 28 deaths, of injuries resulting from television sets toppling onto children (principally aged 12-24 months) were reported to the US Consumer Product Safety Commission, 1990-97. As television sets become larger and stands smaller, manufacturers need to pay attention to securing this top heavy arrangement of equipment. Many sets toppled when children climbed onto furniture to manipulate the controls. A 36 inch $78 \mathrm{~kg}$ television set falling one metre onto a child is roughly equivalent to a 1 year old child weighing $10 \mathrm{~kg}$ falling from a 10 storey height (Pediatrics 1998;102:e32).

Equipment fitted with sharp rotating blades needs to be well designed to prevent injuries to foolhardy operators. Sixty two people aged 11-77 years sustained hand injuries from snowblowers (44 complete finger amputations and 42 partial amputations), most incidents occurring when the operators placed their hands into the exit chutes and contacted the blades while clearing the chutes, the majority of which were not guarded. Voluntary guidelines have been inadequate in the US to enforce safety requirements such as labelling, design, durability of shields and guards, and an automatic stopping switch for these products (American fournal of Orthopedics 1997;26:863-7).

Are electronic security devices effective in preventing child abductions or to keep children from gaining access to roads and swimming pools? Respondents to a survey in Fairfax, Virginia, believed that responsible parents would use security devices, but were not willing to pay much for them (Child: Care, Health and Development 1997;23:415-21). 